\title{
Expiratory Reserve Volume During Slow Expiration With Glottis Opened in Infralateral Decubitus Position (ELTGOL) in Chronic Pulmonary Disease: Technique Description and Reproducibility
}

\author{
Fernanda C Lanza PhD, Cintia Santos Alves PT, Roberta Loures dos Santos PT, \\ Anderson Alves de Camargo MSc, and Simone Dal Corso PhD
}

\begin{abstract}
BACKGROUND: There has not been a detailed description of expiratory reserve volume (ERV) during slow expiration with glottis open in infralateral decubitus position (ELTGOL, for Expiration Lente Totale Glotte Ouverte en infraLatéral) and its reproducibility. The aim of this study was to determine ERV during ELTGOL and to evaluate ERV intra-observer and inter-observer reliability. METHODS: In this prospective study, subjects were 30-70 y of age with chronic lung disease. ELTGOL (an active-passive or active physiotherapy technique) was applied in random order by 3 observers: 2 trained physiotherapists (PT 1 and PT 2) and the subject him/herself. Two ELTGOL compressions (A and B) were applied by PT 1, PT 2, and the subject. RESULTS: Thirty-two subjects were evaluated with moderate lung obstruction, $\mathrm{FEV}_{1}: 47.7 \pm 15.4$, and ERV: $61.7 \pm 29.4$. The mean value of ERV for PT 1 was $51.4 \pm 24.8 \%$; for PT 2, it was $54.3 \pm 31.8 \%$; and for the subject, it was $53.5 \pm 26.2 \%(P=.49)$. Considering the mean value of ERV, the ELTGOL mobilized more than $80 \%$ of ERV. There was good reliability intra-PT: PT 1, intraclass correlation coefficient (ICC) $0.85(0.70-0.93), P<.0001$; PT 2, ICC $0.90(0.80-0.95), P<.0001$, and inter-PT (ICC 0.86 [95\% CI 0.71-0.93], $P<.001)$. The Bland-Altman plot with mean bias and limits of agreement for ERV of PT 1 and PT 2 was $-3.3(-42.7$ to 35.9). CONCLUSIONS: ELTGOL mobilized more than $80 \%$ of ERV in subjects with moderate airway obstruction; there is no difference in ERV exhaled during the technique applied by a physiotherapist or by the subject. ELTGOL is a reproducible technique, determined by inter- and intra-observer testing. Key words: physiotherapy (techniques); reproducibility of results; pulmonary disease; chronic obstructive; respiratory therapy. [Respir Care 2015;60(3):406-411. (C) 2015 Daedalus Enterprises]
\end{abstract}

\section{Introduction}

Chest physiotherapy has been used in patients with obstructive lung disease to improve mucociliary clearance. ${ }^{1}$ The ELTGOL technique (for Expiration Lente Totale Glotte

Drs Lanza and Dal Corso and Mr de Camargo are affiliated with the Postgraduate Program in Rehabilitation Sciences, Universidade Nove de Julho (UNINOVE), São Paulo, Brazil. Ms Alves and Ms dos Santos are affiliated with the School of Physiotherapy, Health Department, UNINOVE, São Paulo, Brazil.

Ms Alves was supported by grant 2012/12020-3 from the São Paulo Research Foundation, Brazil,. The authors have disclosed no conflicts of interest.
Ouverte en infraLatéral, meaning slow expiration with glottis open in infralateral decubitus position) was first described by Guy Postiaux in the 1990s. ${ }^{2}$ This chest physiotherapy technique uses a lateral posture, and the aim is to control the patient's expiratory flow rate to avoid airway compression and increase mucus clearance. Several authors have studied ELTGOL in subjects with chronic lung diseases. ${ }^{3-7}$ Martins et $\mathrm{al}^{3}$ reported an increase in mucus

\footnotetext{
Correspondence: Fernanda C Lanza, PhD, Postgraduate Department, Universidade Nove de Julho, Rua Vergueiro 235/249, São Paulo, SP 01504001, Brazil. E-mail: lanzafe@gmail.com.
}

DOI: $10.4187 /$ respcare. 03384 
clearance in the peripheral area in subjects with COPD after ELTGOL by radio aerosol inhalation, even though Kodric et $\mathrm{al}^{7}$ observed limited benefits (no difference at hospital discharge) in subjects with COPD with exacerbations compared to a control group.

Since the first study of ELTGOL, there has not been a detailed description of expiratory volume during the technique. It is assumed that ELTGOL deflates the lung to expiratory reserve volume (ERV), ${ }^{2}$ but, to our knowledge, this assumption is unproven for this technique. It is necessary to quantify the ERV during ELTGOL because the benefit of this technique is based on air movement in the expiratory phase. If the ERV is not exhaled, there may have been airway compression, which could be caused by severe obstructions or by inadequate performance by the patient. Our group recently described the effects of prolonged slow expiration technique, ${ }^{8}$ a chest physiotherapy developed based on ELTGOL. We determined the percentage of ERV during prolonged slow expiration technique, and although prolonged slow expiration technique was based on ELTGOL, there are differences between the two methods.

Some chest physiotherapy techniques, including ELTGOL, are applied manually. ${ }^{9}$ Manual techniques may be influenced by many situations, including physiotherapist experience, which may result in variability of the technique. The reproducibility of physiotherapy maneuvers has been described previously, and its variability depends on the technique and the level of training of the professional applying it. ${ }^{10-12}$ The variability of ELTGOL has not previously been evaluated; it is an important issue because it may affect ERV.

The aim of this study was to determine ERV during ELTGOL and to evaluate the intra-observer and inter-observer reliability of the ELTGOL technique.

\section{Methods}

This cross-sectional study was performed in the clinical exercise physiology laboratory of the University Nove de Julho, São Paulo, Brazil. Subjects between 30 and 70 y old with non-fibrocystic bronchiectasis were included in the study. We excluded subjects who could not perform the tests or who had chest wall deformities or cardiovascular or neurologic diseases. Written informed consent was obtained from all of the subjects, and the local ethics committee approved the study (study 480315).

Spirometry was performed with a calibrated pneumotachograph (CPFS/D USB; Medical Graphics, St. Paul, Minnesota). The technical procedures and the acceptability and reproducibility criteria were as recommended by the American Thoracic Society. ${ }^{13}$ All of the subjects completed at least three acceptable forced (FVC) and slow vital capacity maneuvers. We recorded $\mathrm{FVC}, \mathrm{FEV}_{1}$,

\section{QUICK LOOK}

\section{Current knowledge}

A number of techniques to enhance mucociliary clearance in patients with chronic lung disease have been developed; however, evidence of efficacy is lacking. The use of slow expiration with glottis open in infralateral decubitus position (ELTGOL) is a technique combining lateral posture with the aim of controlling expiratory flow to avoid airway collapse and increase mucus clearance. Rib cage and abdominal compression is also applied.

\section{What this paper contributes to our knowledge}

In a group of subjects with bronchiectasis, the ELTGOL technique mobilized $80 \%$ of the subjects' predicted expiratory reserve volume. There was no difference in the volume mobilized between self-administration of the technique or assistance by a therapist. ELTGOL was a reproducible technique, as determined by inter- and intra-observer testing. No impact on secretion mobilization was determined.

$\mathrm{FEV}_{1} / \mathrm{FVC}$, and ERV. The predicted values were based on reference values for Brazilian adults. ${ }^{14}$

Body mass was measured to the nearest $0.1 \mathrm{~kg}$ using a calibrated balance (110F; Welmy, São Paulo, Brazil), and body height was determined to the nearest $0.5 \mathrm{~cm}$ using a stadiometer. Body mass index was calculated as the ratio of weight to height in meters squared.

ELTGOL is defined as an active-passive or active technique. ${ }^{2}$ The active technique was applied by the subject. The subject was placed in the lateral decubitus position and carried out slow expiration with the glottis open. To maintain an open glottis, the subject used a mouthpiece, so expiration was performed with the mouthpiece in lateral decubitus. When the active-passive technique was applied, the subject was in the same position (lateral decubitus), with a mouthpiece to maintain the open glottis, and a physiotherapist (PT) positioned behind the subject. One hand of the PT was positioned at the subject's thorax, and the other hand at the abdomen. The PT asked the subject to perform a slow expiration, and at the same time, the PT exerted a thoracic and abdominal compression. ELTGOL was applied by 3 different observers in random order: 2 trained, graduate physiotherapists (PT 1 and PT 2) and the subject. Randomization was done using an opaque envelope containing the observer's abbreviation (PT 1, PT 2, and subject). Two ELTGOL compressions (A and B) were applied by PT 1, PT 2, and the subject (PT 1: compressions A and B; PT 2: compressions A and B; and subject: compressions A and B, Fig. 1). During the technique, ERV 


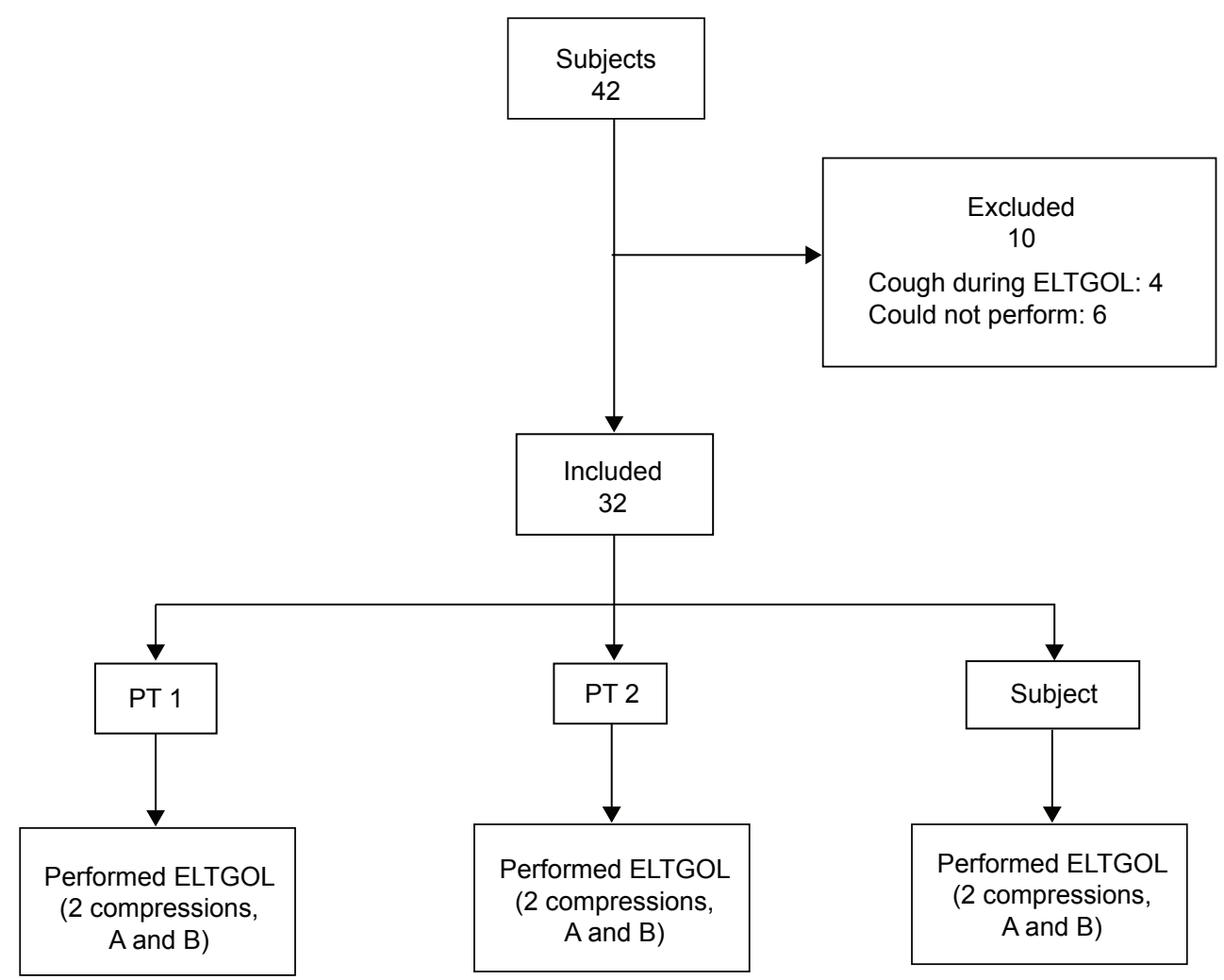

Fig. 1. Study flow. Expiratory reserve volume was evaluated at compressions $A$ and B. PT = physiotherapist, ELTGOL $=$ slow expiration with glottis open in lateral posture.

was evaluated by a spirometer connected to the subject's mouth. The ERV was described as percent of predicted (\%pred).

\section{Statistical Analysis}

The normality of the data were assessed and confirmed by the Kolmogorov-Smirnov test. The variables are expressed as mean $\pm \mathrm{SD}$. A one-way ANOVA was performed to compare ERV among the observers (PT 1, PT 2, and subject). Two-way ANOVA was performed to compare ERV according to the lung function severity (mild, moderate, and severe) among the observers (PT 1, PT 2, and subject). A paired $t$ test was used to compare ERV between compressions A and B. To establish the reliability, ICC and $95 \%$ CI were calculated for ERV intra-PT (compression $\mathrm{A} \times \mathrm{B}$ ) and inter-PT (PT 1 vs PT 2) values. For the inter-PT reliability analysis, the best value of ERV from each PT was selected. The ICC was characterized as follows: good reliability $0.80-1.0$; fair reliability $0.60-$ 0.79 ; and poor reliability $<0.60 .{ }^{15}$ The agreement limits of intra-PT and inter-PT were investigated by plotting the individual ERV differences against their means (BlandAltman analysis). ${ }^{16}$ The significance level for all tests was set at $P<.05$. Statistical analysis was performed using SPSS 14.0 (SPSS, Chicago, Illinois).

\section{Results}

Forty-two subjects were recruited to the protocol; $10 \mathrm{did}$ not complete the study (4 coughed during the technique, and 6 did not understand the ELTGOL technique) (Fig. 1). Thus, 32 subjects were evaluated (17 female); 30 (94\%) were taking antibiotics continuously, and $8(25 \%)$ were taking inhaled corticosteroids. The demographic characteristics are described in Table 1.

The mean value of ERV (compressions A and B) mobilized during ETGOL for PT 1 was $51.4 \pm 24.8 \%$ pred, for PT 2 it was $54.3 \pm 31.8 \%$ pred, and for subject it was $53.5 \pm 26.2 \%$ pred; there were no significant differences $(P=.49)$. The mean value of ERV for these 3 different observers $(52.5 \pm 28.0)$ was higher than $80 \%$, based on the subject's ERV $(61.7 \pm 29.4)$ obtained by spirometry (Fig. 2). There were no differences between compressions $(\mathrm{A} \times \mathrm{B})$ for each observer $(P>.05$; Table 2$)$.

Considering the lung function severity (mild, moderate, or severe), there was no difference in the ERV between PT 1, PT 2, and subject (Table 3).

There was good reliability intra-PT: PT 1 , ICC 0.85 [0.70-0.93], $P<.0001$; PT 2, ICC 0.90 [0.80-0.95], $P<.0001$. The Bland-Altman plot for ERV with mean bias and limits of agreement of compressions A and B of PT 1 was 1.1 ( -33.7 to $35.9 \%$ pred) (Fig. 3A), and for 
Table 1. Baseline Characteristics of Subjects

\begin{tabular}{lc}
\hline \hline & Mean $\pm \mathrm{SD}$ \\
\hline Age (y) & $55 \pm 12$ \\
$\mathrm{BMI}\left(\mathrm{kg} / \mathrm{m}^{2}\right)$ & $26.2 \pm 6.1$ \\
$\mathrm{FVC}(\mathrm{L}, \%$ pred$)$ & $2.2 \pm 0.8(65.3 \pm 16.1)$ \\
$\mathrm{FEV}_{1}(\mathrm{~L}, \%$ pred $)$ & $1.2 \pm 0.5(47.7 \pm 15.4)$ \\
$\mathrm{FEV}_{1} / \mathrm{FVC}$ & $57.0 \pm 12.2$ \\
$\mathrm{ERV}^{(\mathrm{L}, \% \text { pred})}$ & $0.6 \pm 0.3(61.7 \pm 29.4)$ \\
$\mathrm{ERV}$ during ELTGOL $(\mathrm{L}, \%$ pred $)$ & $0.5 \pm 0.3(52.5 \pm 28.0)$ \\
& \\
$N=32$. & \\
BMI $=$ body mass index & \\
$\%$ pred $=$ percent of predicted & \\
ERV $=$ expiratory reserve volume & \\
ELTGOL = slow expiration with glottis open in infralateral decubitus position
\end{tabular}

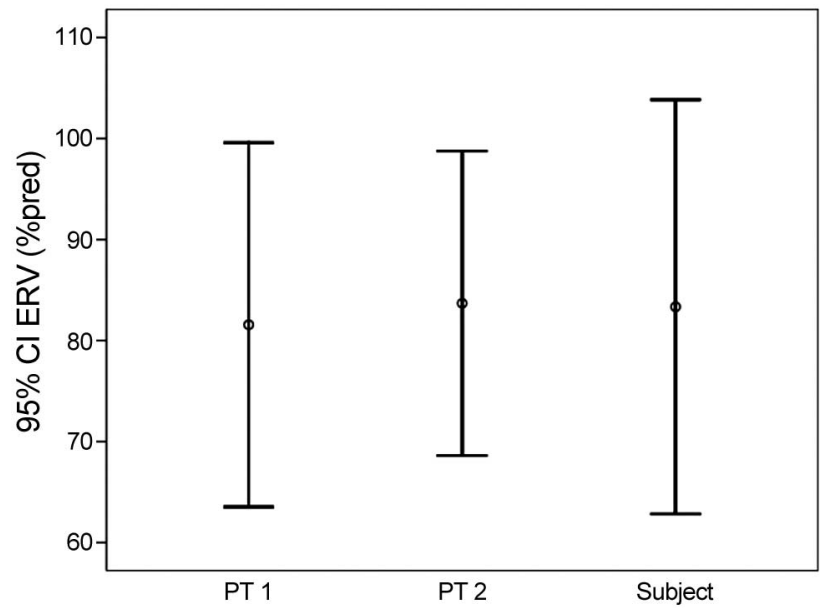

Fig. 2. Error bars of expiratory reserve volume (ERV, based on the ERV of the subject's spirometry) for each evaluator. Data are shown as mean $\pm \mathrm{SD}$. PT $=$ physiotherapist.

Table 2. Expiratory Reserve Volume During ELTGOL for the Evaluators

\begin{tabular}{lccc}
\hline & Compression A & Compression B & $P$ \\
\hline PT1 & $51.9 \pm 24.8$ & $50.7 \pm 26.5$ & .71 \\
PT2 & $54.8 \pm 33.0$ & $55.3 \pm 32.1$ & .89 \\
Subject & $56.9 \pm 27.8$ & $57.0 \pm 23.2$ & .97
\end{tabular}

Expiratory reserve volume (percent of predicted) is expressed as mean $\pm \mathrm{SD}$. $\mathrm{PT}=$ physiotherapist

compressions A and B of PT 2 it was 0.46 ( -37.6 to $38.6 \%$ pred) (Fig. 3B).

There was no difference between the best ERV of PT 1 and PT 2 (51.9 \pm 24.8 vs 55.3 \pm 32.1 , respectively, $P=.35$ ). There was good reliability between the ERV of PT 1 and PT 2 (ICC 0.86 [95\% CI 0.71-0.93], $P<.001$ ), and the Bland-Altman plot with mean bias and limits of agreement
Table 3. Expiratory Reserve Volume During ELTGOL Considering the Lung Function Severity Between the Evaluators

\begin{tabular}{lcccc}
\hline \hline & ERV PT1 & ERV PT2 & ERV Subject & $P$ \\
\hline Mild $(n=8)$ & $65.7 \pm 25.4$ & $73.1 \pm 38.4$ & $64.5 \pm 20.2$ & .34 \\
Moderate $(n=16)$ & $48.5 \pm 24.0$ & $53.1 \pm 30.5$ & $57.9 \pm 31.9$ & .43 \\
Severe $(n=8)$ & $47.7 \pm 24.1$ & $41.0 \pm 24.2$ & $44.3 \pm 25.4$ & .39 \\
$P$ & .35 & .47 & .52 & \\
& \multicolumn{5}{l}{} \\
Expiratory reserve volume (percent of predicted) is expressed as mean \pm SD. \\
ELTGOL = slow expiration with glottis open in infralateral decubitus position \\
ERV = expiratory reserve volume \\
PT =physiotherapist
\end{tabular}

for ERV of PT 1 and PT 2 was -3.3 (-42.7 to 35.9\%pred); (Fig. 3C).

\section{Discussion}

After evaluating subjects with chronic lung disease, the ERV mobilized during the ELTGOL technique was higher than $80 \%$. There were no differences in volume exhaled between the active-passive (applied by a physiotherapist) and active (applied by the subject) techniques, and there was good intra- and inter-observer reliability of ELTGOL.

The ELTGOL technique was developed to increase mucus clearance and improve expiratory volume in subjects with chronic lung disease. $2,3,5$ The technique is based on the expiratory phase, which has to be prolonged and slow. Although ELTGOL has been used since the 1990s, to our knowledge, this is the first description of the amount of ERV exhaled using this technique.

Subjects with chronic lung disease usually have dynamic airway collapse. Several techniques have been described to improve the expiratory phase and avoid premature airway closure in obstructive subjects; $;, 17-20$ one such technique is ELTGOL. The slow expiration with open glottis performed during ELTGOL increases expiratory time. This justifies the amount of volume exhaled during the technique, which was higher than $80 \%$, based on the mean ERV of the subject. End-expiratory lung volume and residual volume have been studied after pursed-lip breathing ${ }^{17,18}$ (an expiratory exercise that prolongs the expiratory phase) and ELTGOL, ${ }^{6}$ but not ERV, as in the present study.

In most studies of ELTGOL, the technique was performed by a physiotherapist; however, it is possible for the subject to execute the technique on his/her own. We did not expect that the ERV exhaled during ELTGOL applied by a physiotherapist would be similar to the results of the subjects applying it by themselves. Our hypothesis was that the compression applied to the thorax and abdomen by the physiotherapist during active-passive ELTGOL would increase pressure in the respiratory system, which should 

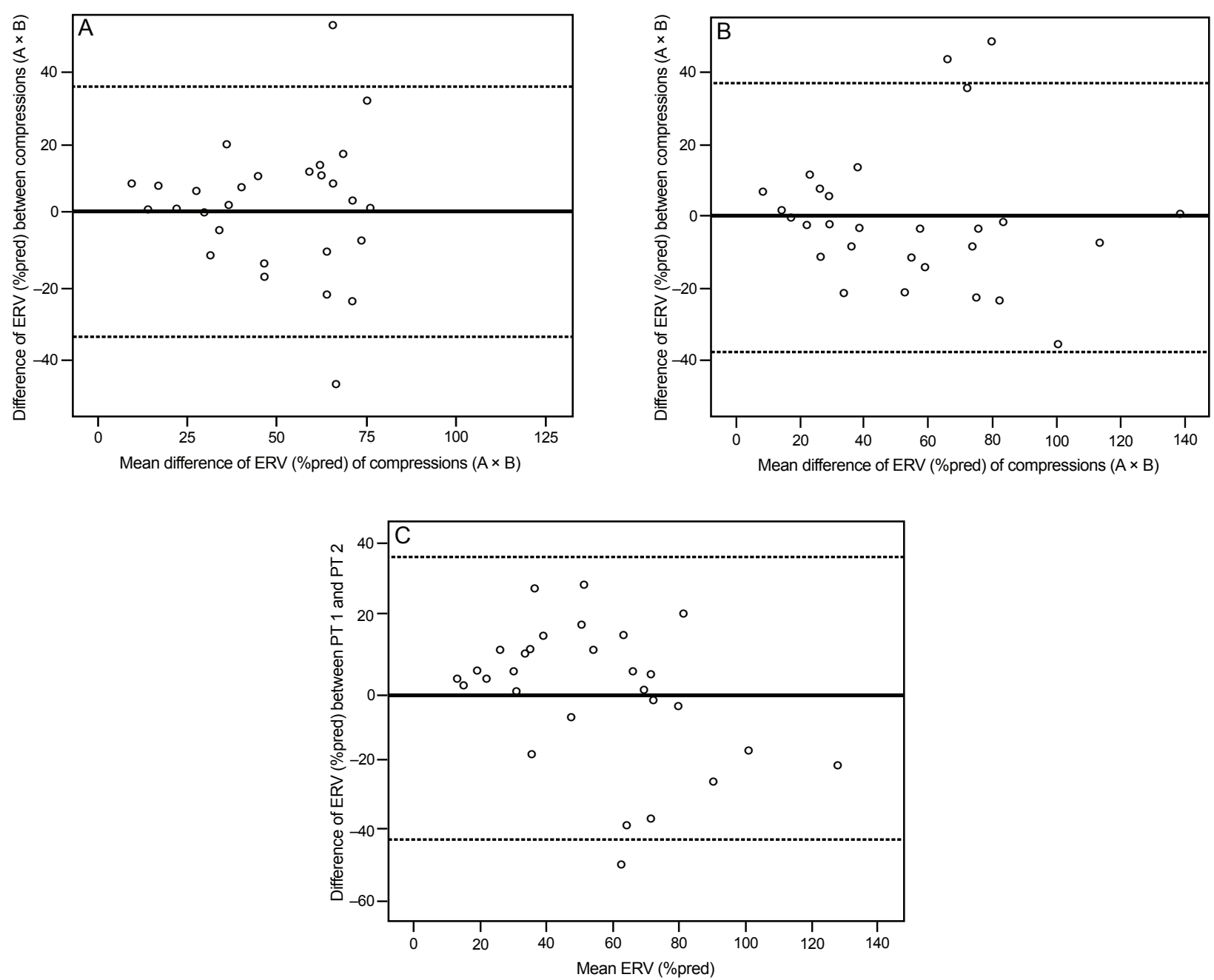

Fig. 3. Bland-Altman plots of the expiratory reserve volume (ERV\%pred). A: compressions A and B of physiotherapist 1 (PT 1) and B: PT 2; C: difference between PT 1 and PT 2. The solid lines indicate the reference mean bias, and the dashed lines indicate the central mean bias and the upper and lower limits of agreement between the observers.

improve the volume of air exhaled by the subject; however, this did not occur. We cannot definitively determine the reason for these results, even though disease severity was a possible answer to this question; lung function severity did not influence ERV during ELTGOL, as shown in Table 3. Nevertheless, the similarities between the results achieved by the physiotherapists and the subjects for ERV during ELTGOL will allow out-patients to perform the technique by themselves at home or in the hospital, after being trained by a physiotherapist.

In the present study, ELTGOL was considered a reproducible technique. The reliability of manual techniques is important for determining the variability of a method, because its effectiveness might be different depending on who applies it. The reliability of different evaluations in clinical practice has been described for the walking test, ${ }^{21}$ respiratory muscle test, ${ }^{22}$ chest wall mobility, ${ }^{10}$ and for other specialties, such as orthopedic diseases. ${ }^{23}$
There was little inter-observer variability between PT 1 and PT 2 (ICC 0.86 [95\% CI 0.71-0.93]), which we expected because both of them were well trained to apply the technique. We found similar results when we compared intra-observer reproducibility (PT 1, ICC 0.85 [0.70-0.93]; PT 2, ICC 0.90 [0.80-0.95]). Even though ELTGOL is a manual technique, which could vary the intensity of the thorax compressions in the active-passive technique, there was little variability between the compressions applied in the same treatment.

Various methods, such as ICC and the Bland-Altman analysis, can be used to express variability between measures. In the present study, the Bland-Altman analyses showed that the bias ratio was close to zero inter- and intra-observer, which is a good indicator of reliability. We observed large limits of agreement inter- and intra-observer (mean $35 \%$ predicted of ERV), which means that a variation of $35 \%$ of ERV is expected when ELTGOL is 
applied. This appears to be a big difference, but ERV variability was not previously determined, as it was with $\mathrm{FEV}_{1}$ and FVC. ${ }^{13}$ Based on our results, we can conclude that a variability of $35 \%$ of ERV during ELTGOL is expected. For example, if a subject with $0.7 \mathrm{~L}$ ERV was included in a regular ELTGOL chest physiotherapy treatment, after intervention, we would expect a minimal change in ERV of $0.24 \mathrm{~L}$ ( $35 \%$ of $0.7 \mathrm{~L}$ ) to be considered effective.

There are some limitations to the present study. We did not test reliability between physiotherapists by difference in education level; thus, we do not know if the reliability is going to be the same in different groups of specialized PTs. To our knowledge, the variability of ERV measured by spirometry is not known, which may have limited the interpretation of the Bland-Altman limits of agreement. As such, we assumed an improvement of $35 \%$ of ERV to determine ELTGOL effectiveness.

\section{Conclusions}

In conclusion, we measured ERV mobilized during ELTGOL (approximately $80 \%$ based on the subject's ERV by spirometry) and determined that there is no difference in ERV exhaled during the technique when applied by a physiotherapist or by the subject. The ELTGOL is a reproducible technique determined by inter- and intra-observer testing.

\section{REFERENCES}

1. Holland AE, Button BM. Is there a role for airway clearance techniques in chronic obstructive pulmonary disease? Chron Respir Dis 2006;3(2):83-91.

2. Postiaux G, Lens E, Alsteens G, Portelange A. Efficacité de l'expiration lente totale glotte ouverte en décubitus infrateral (ELTGOL): sur la toilette en périphérie de l'arbre trachéobronchique. Ann Kinésithér 1990;17(3):87-99.

3. Martins JA, Dornelas de Andrade A, Britto RR, Lara R, Parreira VF. Effect of ELTGOL on mucus clearance in stable patients with chronic bronchitis. Respir Care 2012;57(3):420-426.

4. Bellone A, Lascioli R, Raschi S, Guzzi L, Adone R. Chest physical therapy in patients with acute exacerbation of chronic bronchitis: effectiveness of three methods. Arch Phys Med Rehabil 2000;81(5): 558-560.

5. Souza Pinto V, Bammann RH. Chest physiotherapy for collecting sputum samples from HIV-positive patients suspected of having tuberculosis. Int J Tuberc Lung Dis 2007;11(12):1302-1307.

6. Guimarães FS, Moço VJ, Menezes SL, Dias CM, Salles REB, Lopes AJ. Efeitos da ELTGOL e do Flutter nos volumes pulmonares dinâmi- cos e estáticos e na remoção de secreção de pacientes com bronquiectasia. Rev Bras Fisioter 2012;16(2):36-41.

7. Kodric M, Garuti G, Colomban M, Russi B, Porta RD, Lusuardi M, Confalonieri M. The effectiveness of a bronchial drainage technique (ELTGOL) in COPD exacerbations. Respirology 2009;14(3):424428.

8. Lanza FC, Wandalsen G, Bianca AC, Cruz CL, Postiaux G, Solé D. Prolonged slow expiration technique (PSE): description of pulmonary alterations in infants. Respir Care 2011;56(12)1930-1935.

9. Warnock L, Gates A, van der Schans CP. Chest physiotherapy compared to no chest physiotherapy for cystic fibrosis. Cochrane Database Syst Rev. 2013 Sep 4;9:CD001401. doi: 10.1002/ 14651858.CD001401.pub2.

10. Malaguti C, Rondelli RR, de Souza LM, Domingues M, Dal Corso S. Reliability of chest wall mobility and its correlation with pulmonary function in patients with chronic obstructive pulmonary disease. Respir Care 2009;54(12):1703-1711.

11. Bockenhauer SE, Chen H, Julliard KN, Weedon J. Measuring thoracic excursion: reliability of the cloth tape measure technique. Am Osteopath Assoc 2007;107(5):191-196.

12. Caldeira VdaS, Starling CCD, Britto RR, Martins JA, Sampaio RF, Parreira VF. Precisão e acurácia da cirtometria em adultos saudáveis. J Bras Pneumol 2007;33(5):519-526.

13. American Thoracic Society. Standardization of spirometry, 1994 update. Am J Respir Crit Care Med 1995;152(3):1107-1136.

14. Sociedade Brasileira de Pneumologia e Tisiologia. Diretrizes para testes de função pulmonar. J Pneumol. 2002;28(Suppl 3):S1-S238.

15. Atkinson G, Nevill AM. Statistical methods for assessing measurement error (reliability) in variables relevant to sports medicine. Sports Med 1998;26(4):217-238.

16. Bland JM, Altman DG. Statistical methods for assessing agreement between two methods of clinical measurement. Lancet 1986;1(8476): 307-310.

17. Bianchi R, Gigliotti F, Romagnoli I, Lanini B, Castellani C, Grazzini M, Scano G. Chest wall kinematics and breathlessness during pursedlip breathing in patients with COPD. Chest 2004;125(2):459-465.

18. Spahija J, de Marchie M, Grassino A. Effects of imposed pursed-lips breathing on respiratory mechanics and dyspnea at rest and during exercise in COPD. Chest 2005;128(2):640-650.

19. Chakravorty I, Chahal K, Austin G. A pilot study of the impact of high-frequency chest wall oscillation in chronic obstructive pulmonary disease patients with mucus hypersecretion. Int J Chron Obstruct Pulmon Dis 2011;6:693-699.

20. Osadnik CR, McDonald CF, Jones AP, Holland AE. Airway clearance techniques for chronic obstructive pulmonary disease. Cochrane Database Syst Rev. 2012 Mar 14;3:CD008328. DOI: 10.1002/ 14651858.CD008328.pub3.

21. Opasich C, Pinna GD, Mazza A, Febo O, Riccardi PG, Capomolla S, et al. Reproducibility of the six-minute walking test in patients with chronic congestive heart failure: practical implications. Am J Cardiol 1998;81(12):1497-1500.

22. Romer LM, McConnell AK. Inter-test reliability for non-invasive measures of respiratory muscles functions in healthy humans. Eur J Appl Physiol 2004;91(2):167-176.

23. May S, Littlewood C, Bishop A. Reliability of procedures used in the physical examination of non-specific low back pain: a systematic review. Aust J Physiother. 2006;52(2):91-102. 